Check for updates

Cite this: RSC Adv., 2018, 8, 20648

Received 16th April 2018 Accepted 29th May 2018

DOI: $10.1039 / \mathrm{c} 8 \mathrm{ra03235a}$

rsc.li/rsc-advances

\section{Molecule adsorption and corrosion mechanism of steel under protection of inhibitor in a simulated concrete solution with $3.5 \% \mathrm{NaCl}$}

\author{
Zhifeng Zhang, ${ }^{\mathrm{ab}}$ Fengjuan Wang, ${ }^{\mathrm{ab}}$ Yao Liu, ${ }^{\mathrm{ab}}$ Shengping Wu, ${ }^{\mathrm{ab}}$ Weihua Li, ${ }^{\mathrm{c}}$ Wei Sun, ${ }^{\mathrm{ab}}$ \\ Dong Guo and Jinyang Jiang $(\mathbb{D}$ *ab \\ Herein, the protective performance of a new triazole inhibitor for carbon steel was studied by \\ electrochemical methods. Potentiodynamic polarization curves showed that the anti-corrosion \\ efficiency improved with increasing concentrations of the inhibitor and the results show that it is 22 \\ times corrosion resistance efficiency for inhibitor compared to bare aggressive solution. X-ray \\ photoelectron spectroscopy showed that the film adsorbed well on the carbon steel surface. The \\ scanning vibrating electrode technique demonstrated the corrosion process of carbon steel with and \\ without the protection of inhibitor. Thus, a mechanism for the corrosion process was proposed and the \\ behavior of carbon steel under the protection of the inhibitor was discussed.
}

\section{Introduction}

The use of reinforced concrete as a building material in bridges, architecture, ports, underground structures, etc., has increased over time, worldwide. ${ }^{1}$ Therefore, it is imperative to study the working performance, and anti-corrosive and fire-resistant properties of reinforced concrete; especially, the anticorrosion character is important, since it has been the main reason for many serious accidents and leads to billions of dollars in expenses for maintenance. ${ }^{2}$ Reinforced concrete structures are exposed to many corrosive mediums, such as oil, waste water, $\mathrm{CO}_{2}$, and aggressive ions like $\mathrm{SO}_{4}{ }^{2-}$ and $\mathrm{Cl}^{-}$, which can severely affect the adhesive property of cement and acidize the concrete, thus lowering the bond stress between concrete and steel, causing the steel to rust and undergo structure failure. ${ }^{3}$ Damage by corrosion is the primary reason for structural disintegration of steel. Consequently, it is imperative to solve the corrosion problem and build a protective parclose for the reinforced concrete from the outside aggressive environment. Many methods have been employed to overcome corrosion, such as by using stainless steel, cathodic protection, inorganic inhibitors and coatings, and low alloy steels; however, these are complicated, environmentally hazardous, and uneconomical. ${ }^{4,5}$ Hence, many novel, environmentally friendly, and economical methods, such as the use of enamel coatings,

${ }^{a}$ School of Materials Science and Engineering, Southeast University, Nanjing 211189, China. E-mail: jiangjinyang16@163.com

${ }^{b} J i a n g s u$ Key Laboratary of Construction Materials, Southeast University, Nanjing 211189, China

'Institute of Oceanology, Chinese Academy of Sciences, Qingdao, 266071, China ${ }^{d}$ Naval Institute of Engineering Design and Research, PLA, Beijing, 100070, China corrosion-resistant steels, and green inhibitors, have been proposed and widely used. ${ }^{6,7}$ Inhibitors can effectively prevent steel corrosion, thus providing high inhibition efficiency and migration character in concrete. It is not only useful for new constructions, but also for existing structures. The molecule of an inhibitor can adsorb well on the surface of steel by physisorption or chemisorption, and prevents the aggressive $\mathrm{Cl}^{-}$ ions from destroying the passive film formed on the surface of steel under an alkaline concrete environment. ${ }^{8}$ The fraction of coverage and cohesion on the surface is a vital influential factor for inhibition efficiency. It is possible to isolate the aggressive ions and water from the steel surface effectively by improving the coverage scale and strengthening the binding. Therefore, it is imperative to understand the mechanism of adsorption and micro-zone corrosion of steel under inhibitor protection.

In particular, Haleem et al. studied the benzotriazole and its derivatives as inhibitor for carbon steel in simulated concrete solution with $\mathrm{Cl}^{-}$ions. It shows that type and concentration of inhibitor play the effect on the inhibition efficiency. Adsorption of the inhibitor on the steel surface and the formation of interfaces complex make the occurrence of inhibition. ${ }^{9}$ Wanees et al. do the research of inhibition of pitting corrosion on carbon steel, in which electrochemical impedance spectroscopy and SEM investigation were used to characteristic the inhibition performance. Also, it showed that benzotriazole and its derivatives are good inhibitors for pitting corrosion of reinforcing steel. ${ }^{10}$

In particular, many researchers have studied inhibitors using traditional electrochemical experiments and quantum studies, ${ }^{11,12}$ however there are only few studies that analyze the corrosion process using scanning electrochemical microscopy (SECM) or scanning vibrating electrode technique (SVET), 


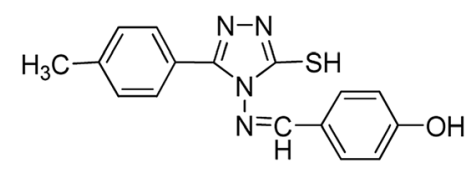

Fig. 1 Structure of inhibitor molecule (SPMT).

which demonstrates the progress of corrosion with time. ${ }^{13}$ Therefore, in our work, the inhibition efficiency was tested by potentiodynamic polarization (Tafel curves). The work focused on the inhibitor adsorption, and subsequent mechanism of corrosion, revealing the adsorption and anti-corrosion mechanism by X-ray photoelectron spectroscopy (XPS) and scanning vibrate electrode technique (SVET), respectively, which is rarely seen in other articles especially the micro-zone corrosion process.

\section{Experimental}

In this work, sodium chloride $(\mathrm{NaCl})$ and sodium hydroxide $(\mathrm{NaOH})$ were purchased from Sinopharm Chemical Reagent Co., Ltd and all other chemicals were obtained from Shanghai Aladdin Bio-Chem Technology Co., Ltd. All the reagents were analytical grade and used directly without further purification. Deionized water was used in whole process.

The structure of the inhibitor molecule, (2-sulfhydryl)-(5phenmethyl)-(1-(4-phenol)-methanimine)-triazole (SPMT), is shown in Fig. 1. Commercial carbon steel Q235 (cutting into $10 \mathrm{~mm} \times 10 \mathrm{~mm} \times 10 \mathrm{~mm}$ and its chemical composition is: $0.14-0.22 \mathrm{C}, 0.30-0.65 \mathrm{Mn},<0.60 \mathrm{Si},<0.05 \mathrm{~S},<0.045 \mathrm{P}$ (wt\%) and Fe balance) was sanding with 400 mesh, 600 mesh and 1000 mesh sandpaper and then polished to perform the open circuit potential (OCP) and potentiodynamic polarization (Tafel) test, which was conducted on a Gamry 3000 using three electrode system, in which carbon steel as working electrode, Pt as counter electrode and saturated calomel electrode (SCE) as reference electrode. ${ }^{14}$ The OCP test time is about $500 \mathrm{~s}$. The Tafel test was carried out from $-250 \mathrm{mV}$ to $+250 \mathrm{mV}$ ( $v s$. OCP) with a potential scanning rate of $0.5 \mathrm{mV} \mathrm{s}^{-1}$. For the X-ray photoelectron spectroscopy (XPS) test, carbon steel was incised to a dimension of $4 \mathrm{~mm} \times 4 \mathrm{~mm} \times 2 \mathrm{~mm}$, and was soaked in a simulated concrete solution with $3.5 \% \mathrm{NaCl}$ and $2.0 \mathrm{mmol} \mathrm{L}^{-1}$ inhibitor for 3 days, following which the test was conducted on a PHI Quantum 2000 with an $\mathrm{Al}-\mathrm{K} \alpha$ radiation source. ${ }^{15}$ After the same treating process of Q235 for XPS test, the scanning vibrating electrode technique (SVET) analysis was carried out an AE scanning electrochemical workstation (SVET, Applicable Electronics) under 3.5\% NaCl solution. ${ }^{16}$ Each cycle was of 15 min until the occurrence of corrosion on the surface of the carbon steel.

\section{Results and discussion}

\subsection{Electrochemical analysis}

3.1.1 OCP analysis. The OCP test results are shown in Fig. 2, in which stable potential values shifted toward positive

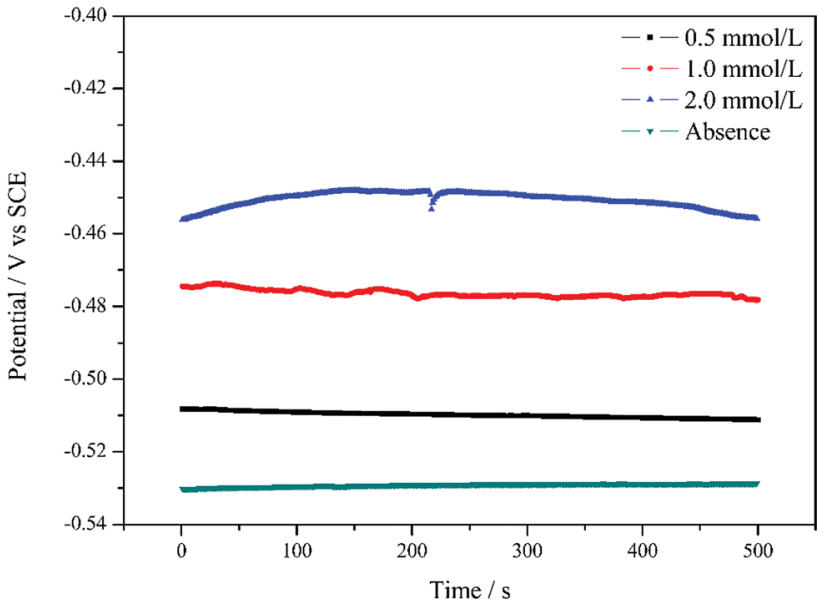

Fig. 2 Open circuit potential (OCP) versus time curves for carbon steel in simulated concrete solution with blank and varied concentrations of inhibitor.

direction gradually with increasing of inhibitor concentration due to the formation of anti-corrosion molecule film which restrain the attack of $\mathrm{Cl}^{-}$ions in solution. In the exposure time of $500 \mathrm{~s}$, potential values are stable at $-0.449,-0.477,-0.510$, $-0.529 \mathrm{~V} v$ s. SCE for blank sample, $0.5 \mathrm{mmol} \mathrm{L}^{-1}, 1.0 \mathrm{mmol} \mathrm{L}^{-1}$ and $2.0 \mathrm{mmol} \mathrm{L}^{-1}$ sample, respectively. According to the change of potential values, we can get that concentrations of inhibitor showed a protective performance for steel rebar in aggressive simulated concrete solution, which may be due to the formation of molecule film on the carbon steel surface. ${ }^{17}$

3.1.2 Tafel analysis. The potentiodynamic polarization test was performed to investigate the protective performance of the inhibitor for carbon steel, as well as the cathodic and anodic corrosion behavior of the carbon steel. ${ }^{18}$ Tafel curves of steel in simulated concrete solution in the absence and presence of various concentrations of the inhibitor are shown in Fig. 3. In the presence of the inhibitor, the cathodic current was largely

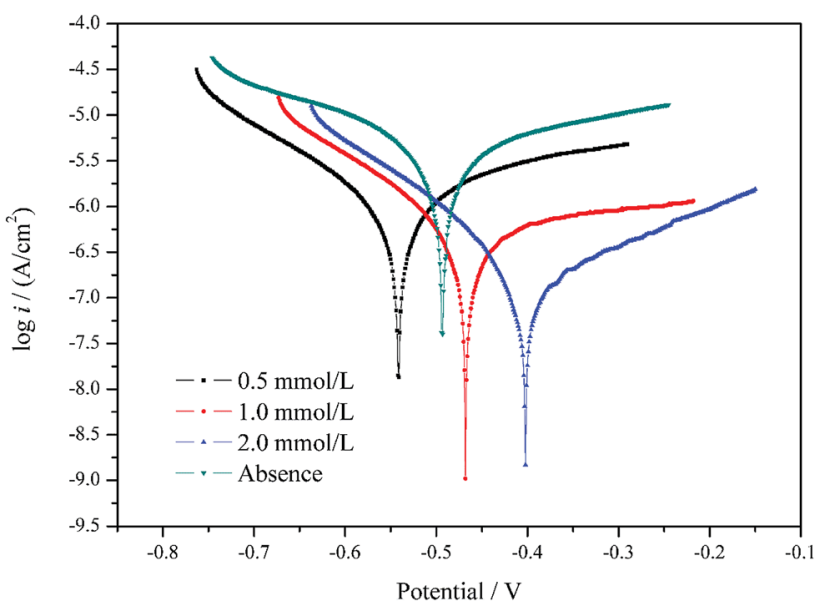

Fig. 3 Potentiodynamic polarization curves for mild steel in simulated concrete solutions with $3.5 \% \mathrm{NaCl}$ and varied concentrations of inhibitor. 
Table 1 Fitted electrochemical parameters from polarization curves

\begin{tabular}{llllll}
\hline $\begin{array}{l}c \\
\left(\mathrm{mmol} \mathrm{L}^{-1}\right)\end{array}$ & $\begin{array}{l}\beta_{\mathrm{a}} \\
\left(\mathrm{mv} \mathrm{dec}^{-1}\right)\end{array}$ & $\begin{array}{l}\beta_{\mathrm{c}} \\
\left(\mathrm{mv} \mathrm{dec}^{-1}\right)\end{array}$ & $\begin{array}{l}E_{\text {corr }} \\
(\mathrm{V} v \mathrm{~s} . \mathrm{SCE})\end{array}$ & $\begin{array}{l}i_{\text {corr }} \\
\left(\mu \mathrm{A} \mathrm{cm}^{-2}\right)\end{array}$ & $\begin{array}{l}\eta \\
(\%)\end{array}$ \\
\hline Absence & 30.03 & -21.41 & -0.4935 & 3.16 & - \\
0.5 & 24.87 & -15.06 & -0.5408 & 0.871 & 72.4 \\
1.0 & 42.73 & -14.10 & -0.4679 & 0.435 & 86.2 \\
2.0 & 22.62 & -11.97 & -0.4022 & 0.142 & 95.5
\end{tabular}

suppressed as compared to anodic current, and the corrosion potential of steel varied with the concentration of the inhibitor.

Electrochemical corrosion parameters were calculated to characteristic corrosion rate, such as corrosion densities $\left(i_{\text {corr }}\right)$ and cathodic Tafel slopes $\left(\beta_{\mathrm{a}}\right.$ and $\left.\beta_{\mathrm{c}}\right)$, in which the former were obtained through the intersection point of anodic and cathodic Tafel straight line slopes and the slope of tangent were $\beta_{\mathrm{a}}$ and $\beta_{\mathrm{c}}$, respectively, and results were listed in Table $1 .^{19}$

From the results, the addition of the inhibitor has an anticorrosive effect on the carbon steel. Especially, an efficiency of 72.4\% and 95.5\% were achieved for low and high concentrations, respectively. And this is equivalent to the inhibition efficiency in ref. 9 and 17. The improved efficiency may be on account of geometry control..$^{20}$ At a low concentration, the inhibitor molecule completely disappeared within the solution or on the surface of steel, and consequently, could cover only a small fraction of the steel. With increasing concentration, however, more molecules could adsorb on the surface, layer by layer, and could thus hamper the movement of aggressive ions that destroy the passive film.

Further, the corrosion rate (CR) can be calculated by corrosion density using the standard equation (eqn (1)) documented in ASTM standard G102. ${ }^{21}$

$$
\mathrm{CR}=K\left[i_{\text {corr }} / \rho A\right] \times \mathrm{EW}
$$

in which, corrosion rate constant $K$ is $3272 \mathrm{~mm}$ per year, equivalent weight (EW) of $\mathrm{Fe}$ is $56 \mathrm{~g}$, density of carbon steel is $7.85 \mathrm{~g} \mathrm{~cm}^{-3}$ and sample area $(A)$ is $1 \mathrm{~cm}^{2}$. Calculated value of corrosion rate is $0.073 \mathrm{~mm}$ per year, $0.020 \mathrm{~mm}$ per year, $0.010 \mathrm{~mm}$ per year and $0.003 \mathrm{~mm}$ per year for ambulance and 0.5, 1.0, $2.0 \mathrm{mmol} \mathrm{L}^{-1}$ inhibitor, respectively. This results reveals that adding inhibitor increasing the anti-corrosion performance, especially $2.0 \mathrm{mmol} \mathrm{\textrm {L } ^ { - 1 }}$ increase the resistance of 22.25 times compared to bare aggressive solution.

Moreover, compared to the inhibitor-free sample, concentration of $0.5 \mathrm{mmol} \mathrm{L}^{-1}$ had the tendency to shift $E_{\text {corr }}$ in the negative direction. However, $E_{\text {corr }}$ gradually moved toward the anodic direction with the addition of the inhibitor, thus effectively enhancing anodic inhibition. Cathodic corrosion was considerably reduced; however, a greater impact was observed for corrosion in the anodic zone. SPMT is a mixed-type inhibitor, due to which the displacement of $E_{\text {corr }}$ was less than $85 \mathrm{mV}$ as compared to that of the inhibitor-free sample in the Tafel curve. $^{22}$

A comparison of the corrosion rate in the anodic zone between the inhibitor-free and $2.0 \times 10^{-3} \mathrm{~mol} \mathrm{~L}^{-1}$ samples

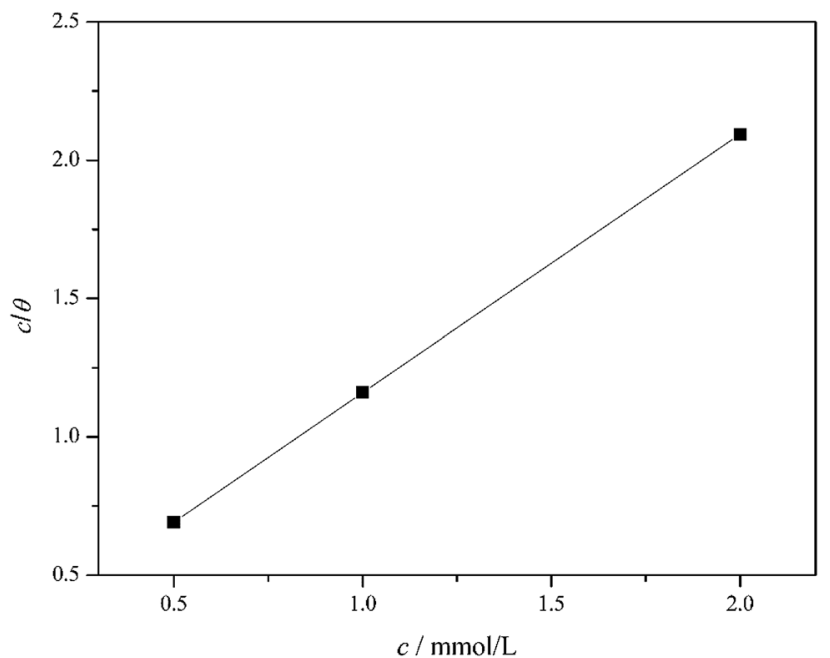

Fig. 4 Langmuir adsorption isotherm for adsorption of inhibitor on carbon steel in simulated concrete solution.

reveals that the high-concentration samples present more severe corrosion than the bare sample (by $\beta_{\mathrm{a}}$ value), though the corrosion current evinces the contrary. A corrosion product model may be used to explain this. First, a high corrosion rate leads to a rapid reaction:

$$
\mathrm{Fe} \rightarrow \mathrm{FeOOH}+\mathrm{Fe}_{2} \mathrm{O}_{3}+\mathrm{Fe}_{3} \mathrm{O}_{4}
$$

This loosens corrosion products of iron oxide attached to the steel surface, which can hamper the movement of $\mathrm{Cl}^{-}$ions and destroy the iron substrate within no time. We call this a "false protection phenomenon", which does not protect carbon steel but only shows a superficial lower reaction rate. This is supported by XPS and SVET analysis, as discussed below.

3.1.3 Adsorption isotherm. In order to elucidate the type of adsorption, adsorption isotherm of inhibitor was build depending on the inhibition efficiency of Tafel test. Here, Langmuir adsorption isotherm was used to study the adsorption behavior of the inhibitor on the surface of carbon steel. The Langmuir adsorption isotherm was shown in eqn $(2)^{23}$ as follows:

$$
c / \theta=1 / K_{\mathrm{ads}}+c
$$

where $c$ is the concentration of inhibitor $\left(\mathrm{mmol} \mathrm{L}^{-1}\right), \theta$ is the coverage equivalent (defined as IE\%) is the equilibrium constant $\left(\mathrm{L} \mathrm{mol}^{-1}\right)$. In Fig. 4, plot of $c / \theta$ versus $c$ is a straight line and the slope is close to 1 , hence Langmuir adsorption isotherm is appropriate for the adsorption behavior of inhibitor on surface of carbon steel. ${ }^{24}$ Further, standard adsorption free energy $\left(\Delta G_{\text {ads }}^{0}\right)$ is got by the value of calculated $K_{\text {ads }}$ and eqn (3):

$$
\Delta G_{\mathrm{ads}}^{0}=-R T \ln \left(55.5 K_{\mathrm{ads}}\right)
$$

where $R, T$ and number of 55.5 is the universal gas constant (J $\left.(\mathrm{mol} \cdot \mathrm{K})^{-1}\right)$, temperature $(\mathrm{K})$ and molar concentration $\left(\mathrm{mol} \mathrm{L}^{-1}\right)$ 
of water in solution, respectively. In this study, the calculated $\Delta G_{\text {ads }}^{0}$ is $-30.792 \mathrm{~kJ} \mathrm{~mol}^{-1}$, which show that the molecule adsorbed on the iron surface is spontaneous and there is physisorption and chemisorption together for the inhibitor molecules adsorbed on iron surface. ${ }^{25}$

\subsection{XPS analysis}

XPS analysis was employed to identify the characteristic elements of the inhibitor, in order to confirm that the molecule film was fully or partly adsorbed on the carbon steel surface, by comparing spectra of the inhibitor-free and added samples, and to confirm the type of bond between iron and the inhibitor molecule. ${ }^{26}$ The XPS spectra, including $\mathrm{C} 1 \mathrm{~s}, \mathrm{O} 1 \mathrm{~s}, \mathrm{Fe} 2 \mathrm{p}$, and $\mathrm{N}$ 1s spectra, are shown in Fig. 5a. Spectra were also assigned to the corresponding species by deconvolution fitting. ${ }^{27}$

Three characteristic peaks can be observed in Fig. $5 \mathrm{~b}$. The peaks at $284.8 \mathrm{eV}$ and $286.3 \mathrm{eV}$ correspond to the presence of the inhibitor, whereas those at $284.6 \mathrm{eV}$ and $285.5 \mathrm{eV}$, to the absence of the inhibitor; these peaks were attributed to the $\mathrm{C}-\mathrm{C}$ bond and $\mathrm{C}=\mathrm{O}$ bond, respectively, which are contaminant hydrocarbons originating from the XPS instrument itself and are observed in both the inhibitor-added and inhibitor-free samples. ${ }^{28}$ A third peak at $288.6 \mathrm{eV}$ is ascribed to $\mathrm{sp}^{2}$-hybridized carbon, which is from the molecule of the inhibitor, and was not detected in the inhibitor-free sample. ${ }^{29}$

The $\mathrm{O} 1 \mathrm{~s}$ spectra for the carbon steel surface can be deconvoluted into three components and are shown in Fig. 5c. The first peak at a binding energy of $529.9 \mathrm{eV}$ and $530.0 \mathrm{eV}$ for the presence and absence of the inhibitor, respectively, is attributed to $\mathrm{Fe}-\mathrm{O}$ bonds, such as $\mathrm{Fe}_{2} \mathrm{O}_{3}$ and $\mathrm{Fe}_{3} \mathrm{O}_{4} \cdot{ }^{30}$ The second peak at $531.8 \mathrm{eV}$ for inhibitor presence and $531.9 \mathrm{eV}$ for inhibitor absence, can be ascribed to the $\mathrm{H}-\mathrm{O}$ bond, from a compound chemisorbed on the surface or FeOOH. ${ }^{31}$ The final peak at $533.0 \mathrm{eV}$ can be assigned to oxygen in the adsorbed water, was only detected in the inhibitor-free sample. ${ }^{32}$

The rough $\mathrm{Fe} 2 \mathrm{p}$ spectrum for the carbon steel surface is shown in Fig. 5a, and exhibits a double peak profile around $711 \mathrm{eV}\left(\mathrm{Fe} \mathrm{2} \mathrm{p}_{3 / 2}\right)$ and $725 \mathrm{eV}\left(\mathrm{Fe} 2 \mathrm{p}_{1 / 2}\right) .{ }^{33}$ The high-resolution Fe $2 \mathrm{p}_{3 / 2}$ XPS spectrum (Fig. $5 \mathrm{~d}$ ) can be deconvoluted into two main peaks. The first peak at a lower binding energy of $706.3 \mathrm{eV}$ and $706.9 \mathrm{eV}$ can be assigned to metallic iron for the inhibitor-added and inhibitor-free samples, respectively. ${ }^{34}$ The second peak at $709.9 \mathrm{eV}$ and $710.6 \mathrm{eV}$ for the inhibitor presence and absence, respectively, can be assigned to iron oxides, such as $\mathrm{FeO}, \mathrm{Fe}_{2} \mathrm{O}_{3}$, $\mathrm{Fe}_{3} \mathrm{O}_{4}$, and $\mathrm{FeOOH}$; this is in agreement with the $\mathrm{O}$ 1s spectra. ${ }^{30,35,36}$ Since peaks of Fe $2 \mathrm{p}$ and $\mathrm{O}$ 1s were detected in both the inhibitor-added and inhibitor-free samples, they cannot serve as evidence of adsorption of the inhibitor molecules on the steel surface.

The high-resolution $\mathrm{N}$ 1s spectra in Fig. 5e show one spectrum for the inhibitor-added sample while that was not detected in the inhibitor-free sample, providing evidence that the investigated inhibitor molecule was chemically adsorbed on the steel surface. The N 1s XPS spectrum can be deconvoluted into two peaks; the first peak located at $398.9 \mathrm{eV}$ is attributed to $\mathrm{C}-\mathrm{N}$ group, ${ }^{28}$ whereas the second peak located at a binding energy of
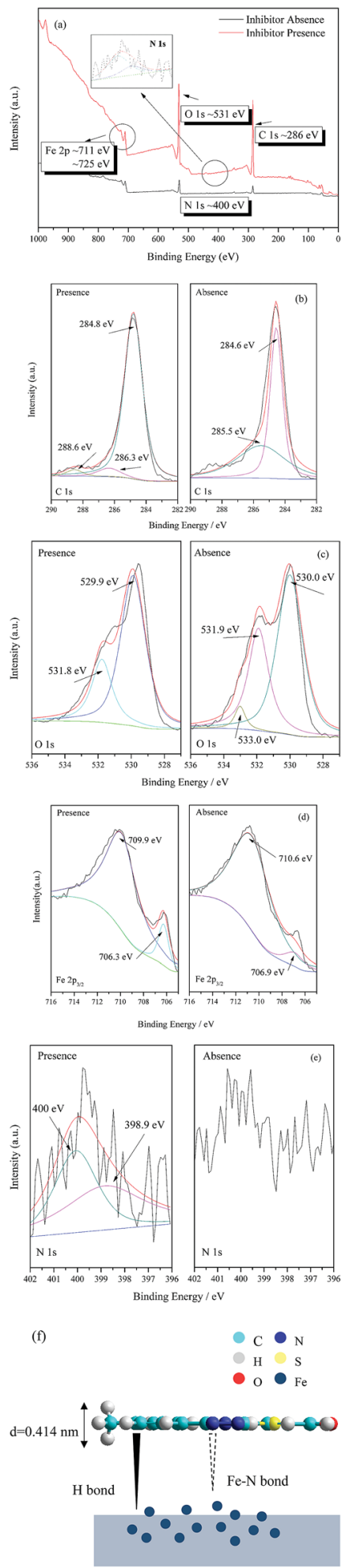

Fig. 5 X-ray photoelectron spectroscopy profiles of (a) full resolution; high resolution (b) $\mathrm{C} 1 \mathrm{~s}$, (c) $\mathrm{O} 1 \mathrm{~s}$, (d) Fe $2 \mathrm{p}_{3 / 2}$, (e) $\mathrm{N} 1 \mathrm{~s}$ for triazole-treated carbon steel and (f) mechanism of inhibitor adsorption.

$400 \mathrm{eV}$ can be ascribed to the Fe-N bond, which arises from the coordination of the nitrogen atom with the iron atom on the surface. ${ }^{37}$ From the above XPS analysis, we conclude that the inhibitor was adsorbed on the steel surface by the formation of 

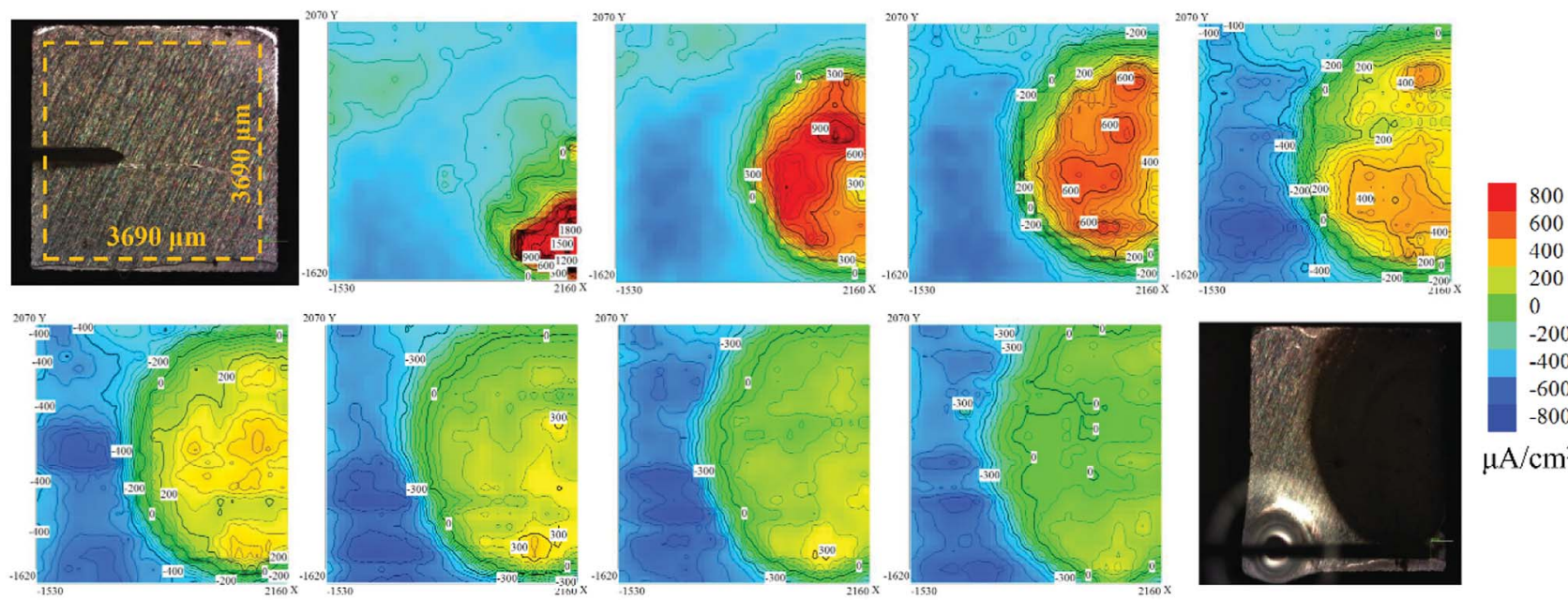

Fig. 6 SVET analysis of triazole-treated sample in 3.5\% $\mathrm{NaCl}$ solutions and optical micrograph.

the Fe-N bond. ${ }^{38} \mathrm{~S}$ was not clearly detected in the XPS spectra, maybe due to its less content. Thus, the adsorption mechanism of the inhibitor on the surface of the carbon steel can be illustrated in Fig. 5f, in which molecule adsorbed on surface of carbon steel due to the formation of $\mathrm{Fe}-\mathrm{N}$ bond and $\mathrm{H}$ bond and we can confirm that it is the combination of chemisorption and physisorption between the molecule and carbon steel.

\subsection{SVET analysis}

SVET is an effective method and is widely used to monitor the localized corrosion of the surface of carbon steel; it not only provides a map of the ion currency generated by corrosion, but also illustrates the progress of corrosion with time..$^{39,40} \mathrm{~A}$ variation of ion currency indicates a change in the corrosion reaction process; therefore, conversely, the corrosion process can be characterized by ion currency. Fig. 6 shows SVET plots of the prepared sample immersed in $3.5 \% \mathrm{NaCl}$ solution for tests of several cycles. In the first test cycle, an intense anodic current was detected in the right corner of the surface, which is the artificial defect area where the inhibitor is absent. With progress of the immersion time, more intense anodic currents were detected in the first three test cycles, indicating that the corrosion proceeded outward from the center of the inhibitor-free zone. Corrosion extension is an interesting phenomenon, in which corrosion starts at the inhibitor-free location; consequently, aggressive ions destroy the interface between the inhibitor molecule and carbon steel surface; this strips the molecule from the surface, and corrosion gradually extends to the inhibitor coverage area. However, the intense anodic current disappears after six test cycles, implying suppression of corrosion at the artificial defect area. This suppression may be caused by the corrosion products covered on the surface which prevent ionic flow; this is different from the protection mechanism of the inhibitor covering the steel surface. Meanwhile, for the remaining surface, the currents remained constant over the test cycles; the inhibitor molecules in these regions were not destroyed, thus presenting better anti-corrosion performance. A flagrant contrast illustrates the anti-corrosion mechanism of the inhibitor, i.e. aggressive ions can only can destroy the uncovered location and strip the molecules at the boundary line gradually, and have no effect on the surface for a stable molecular film. This phenomenon is also clearly seen from the optical images. In the first and last figure of optical images, the area is bright and clean before the corrosion test cycle, but shows rust around the artificial area after several corrosion test cycles; however, the surface is intact for the area covered by the inhibitor, evincing the anti-corrosive effect of the inhibitor. A
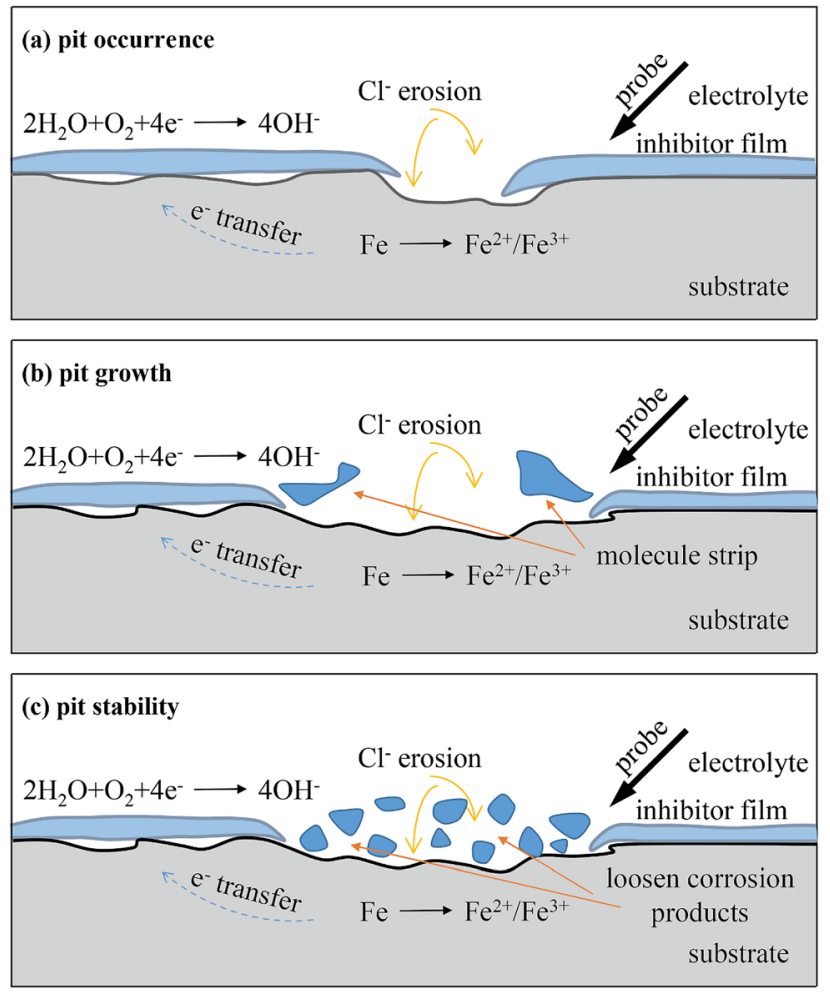

Fig. 7 Illustration of corrosion mechanism under protection of inhibitor molecule by SVET analysis: (a) pit occurrence; (b) pit growth; (c) pit stability. 
schematic diagram of pit corrosion on carbon steel is shown in Fig. 7. In Fig. 7a, under the attack of $\mathrm{Cl}^{-}$ions, corrosion is initiated at the unprotective area with the losing of electron of Fe. With the corrosion reaction, nearby inhibitor molecules was destroyed gradually, as shown in Fig. 7b. Loosen corrosion products assemble on the centralized region but the corrosion reaction was controlled by the firmly molecule which is far from the unprotective area. Therefore, it depicted the protective performance of inhibitor under the aggressive solution.

\section{Conclusions}

A new triazole molecule was tested and the results show that it is an effective corrosion inhibitor under simulated concrete pore solution with aggressive $\mathrm{NaCl}$. And the inhibition efficiency is increased with the increasing of inhibitor concentration and concentration of $2.0 \mathrm{mmol} \mathrm{L}^{-1}$ had the best inhibiting effect in this test. Anti-corrosion process and mechanism for inhibitor under surface of carbon steel was revealed by SVET test, which show corrosion occurred at the artificially destroyed area and gradually eroded the adjacent inhibitor film. However, the area under the inhibitor film was intact throughout the corrosion tests. Therefore, this triazole molecule can be as an effective inhibitor in the protection of carbon steel in marine engineering to resist the attack of $\mathrm{Cl}^{-}$ions and make the steel concrete structure have a longer service life.

\section{Conflicts of interest}

There are no conflicts to declare.

\section{Acknowledgements}

This work was supported by National Key Research and Development Program of China (2016YFC0305100), the National Program on Key Basic Research Project (Grant No. 2015CB655105), and the National Natural Science Foundation of China (Grant No. 51508091 and 51438003).

\section{References}

1 D. M. Yan, G. D. Chen, F. J. Tang and C. L. Wu, Scientia Sinica Technologica, 2015, 45, 293-305.

2 F. J. Tang, G. D. Chen, R. K. Brow, J. S. Volz and M. L. Koenigstein, Corros. Sci., 2012, 59, 157-168.

3 C. H. Wang, W. Sun, J. Y. Jiang, J. D. Han and B. T. Ye, Sci. China: Technol. Sci., 2012, 55, 1359-1364.

4 D. Huang, J. Hu, G. L. Song and X. Guo, Electrochim. Acta, 2011, 56, 10166-10178.

5 Z. Ai, W. Sun, J. Jiang, D. Song, H. Ma, J. Zhang and D. Wang, Materials, 2016, 9, 749.

6 F. J. Tang, G. D. Chen, J. S. Volz, R. K. Brow and M. Koenigstein, Constr. Build. Mater., 2012, 35, 376-384.

7 A. A. Alamiery, F. A. B. Kassim, A. A. H. Kadhum and A. B. Mohamad, Sci. Rep., 2016, 6, 19890.

8 X. Q. Cheng, X. G. Li and C. W. Du, Chin. Sci. Bull., 2009, 54, 2239-2246.
9 S. M. A. E. Haleem, S. A. E. Wanees and A. Bahgat, Corros. Sci., 2014, 87, 321-333.

10 S. A. E. Wanees, A. B. Radwan, M. A. Alsharif and S. M. A. Haleem, Mater. Chem. Phys., 2017, 190, 79-95.

11 M. Yadav, R. R. Sinha, S. Kumar and T. K. Sarkar, RSC Adv., 2015, 5, 70832-70848.

12 X. Zhang, Y. Zheng, X. Wang, Y. Yan and W. Wu, Ind. Eng. Chem. Res., 2014, 53, 14199-14207.

13 K. R. Ansari, M. A. Quraishi, A. Singh, S. Ramkumar and I. B. Obote, $R S C A d v$. , 2016, 6, 24130-24141.

14 J. H. Lin, C. Wang, S. X. Wang, Y. M. Chen, W. He, T. Ze and B. Chen, J. Alloys Compd., 2017, 719, 376-382.

15 A. F. Zatsepin, D. A. Zatsepin, D. W. Boukhvalov, N. V. Gavrilov, V. YaShur and A. A. Esin, J. Alloys Compd., 2017, 728, 759-766.

16 A. S. Gnedenkov, S. L. Sinebryukhov, D. V. Mashtalyar and S. V. Gnedenkov, Corros. Sci., 2016, 102, 269-278.

17 H. S. Lee, H. M. Yang, J. K. Singh, S. K. Prasad and B. Yoo, Constr. Build. Mater., 2018, 173, 443-451.

18 A. Chinnappan, D. X. Ji, C. Baskarc, X. H. Qin and S. Ramakrishn, J. Alloys Compd., 2018, 735, 2311-2317.

19 R. Hasanov, M. Sadıkoglu and S. Bilgic, Appl. Surf. Sci., 2007, 253, 3913-3921.

20 X. Gao, C. Zhao, H. Lu, F. Gao and H. Ma, Electrochim. Acta, 2014, 150, 188-196.

21 S. C. Sahu, A. K. Samantara, M. Seth, S. Parwaiz, B. P. Singh, P. C. Rath and B. K. Jena, Electrochem. Commun., 2013, 32, 22-26.

22 H. W. Tian, W. H. Li, A. Liu, X. Gao, H. Peng, R. Ding, C. Z. Yang and D. P. Wang, Corros. Sci., 2018, 131, 1-16.

23 H. M. A. El-Lateef and A. H. Tantawy, RSC Adv., 2016, 6, 8681-8700.

24 X. He, Y. Jiang, C. Li, W. Wang, B. Hou and L. Wu, Corros. Sci., 2014, 83, 124-136.

25 L. C. Murulana, M. M. Kabanda and E. E. Ebenso, RSC Adv., 2015, 5, 28743-28761.

26 S. Manasa, A. Jyothirmayi, T. Siva, S. Sathiyanarayanan, K. V. Gobi and R. Subasri, J. Alloys Compd., 2017, 726, 969977.

27 M. Chevalier, F. Robert, N. Amusant, M. Traisnel, C. Roos and M. Lebrini, Electrochim. Acta, 2014, 131, 96-105.

28 V. K. Gupta, T. Eren, N. Atar, M. L. Yola, C. Parlak and H. Karimi-Maleh, J. Mol. Liq., 2015, 208, 122-129.

29 N. Song, X. L. Wu, S. X. Zhong, H. J. Lin and J. R. Chen, J. Mol. Liq., 2015, 212, 63-69.

30 K. Boumhara, M. Tabyaoui, C. Jama and F. Bentiss, J. Ind. Eng. Chem., 2015, 29, 146-155.

31 B. Hu, X. Mei, X. Li, J. Hu, D. Xu, J. Ma and Y. Huang, J. Mol. Liq., 2017, 237, 1-9.

32 X. Cao, W. Yan, C. Jin, J. Tian, K. Ke and R. Yang, Electrochim. Acta, 2015, 180, 788-794.

33 F. Zou, X. H. Hu, Z. Li, Q. Long, C. C. Hu, R. Zeng, Y. Jiang and Y. H. Huang, Adv. Mater., 2014, 26, 6622-6628.

34 V. D. Castro and S. Ciampi, Surf. Sci., 1995, 331-333, 294299.

35 W. W. Zhang, R. Ma, H. H. Liu, Y. Liu, S. Li and L. Niu, J. Mol. Liq., 2016, 222, 671-679. 
36 L. J. Meng, Z. H. Wang, L. Yang, W. J. Ren, W. Liu, Z. D. Zhang, T. Yang and M. P. D. Santos, Appl. Surf. Sci., 2018, DOI: 10.1016/j.apsusc.2018.03.043.

37 P. D. Prabhawalkar, P. M. Raole, D. C. Kothari and M. R. Nair, Vacuum, 1986, 36, 817-820.
38 J. Du, X. L. Liu, W. Liu, Z. Q. Wu and H. Chen, Sci. China: Chem., 2014, 57, 654-660.

39 J. Tedim, A. C. Bastos, S. Kallip, M. L. Zheludkevich and M. G. S. Ferreira, Electrochim. Acta, 2016, 210, 215-224.

40 Q. Ni, X. Xia, J. Zhang, N. Dai and Y. Fan, Electrochim. Acta, 2017, 247, 207-215. 